\title{
O impacto da política de desenvolvimento produtivo no consumo aparen- te e nos níveis de bem-estar: uma análise de equilíbrio geral computável ${ }^{\dagger}$
}

\author{
Daniel Arruda Coronel* \\ André Filipe Zago de Azevedo** \\ Antônio Carvalho Campos ${ }^{* * *}$
}

\begin{abstract}
RESUMO - O objetivo deste trabalho é verificar o impacto das alterações tributárias propostas pela Política de Desenvolvimento Produtivo (PDP) no consumo aparente e nos níveis de bem -estar, por meio do Modelo de Equilíbrio Geral Computável (GTAPinGAMS). Os principais resultados do trabalho indicaram que dos treze setores analisados, dez apresentaram aumentos na relação produção menos exportações e decréscimos na relação importações, ambos sobre o consumo aparente; ou seja, a PDP contribuiu para aumentar ainda mais o viés doméstico do consumo brasileiro na maior parte dos setores analisados, o que é o objetivo de todas as políticas industriais. No que tange aos níveis de bem-estar, observou-se aumento de aproximadamente US\$ 3 bilhões.
\end{abstract}

Palavras-chave: Economia brasileira. Equilíbrio geral. GTAPinGAMS.

\section{INTRODUÇÃO}

Ao assumir a Presidência da República, o governo Lula encontrou um país com estabilidade política e econômica e credibilidade no cenário internacional. Não obstante, o Governo tinha vários desafios, tais como diminuir o desemprego, o risco-país, as dívidas externa e interna, aumentar o crescimento econômico e fomentar o setor industrial. As baixas taxas de crescimento do setor industrial levaram vários economistas, como Bresser-Pereira (2010), a apresentarem argumentos de que o Brasil estava iniciando um processo de desindustrialização, ou seja, um processo de queda da participação do setor industrial na participação do Produto Interno Bruto (PIB). Segundo esse autor, os países desenvolvidos, a partir de certo nível de renda per capita, começaram a se desindustrializar, devido à concorrência de países onde a mão

\footnotetext{
${ }^{\dagger}$ Este trabalho é oriundo da tese de doutorado do primeiro autor, o qual contou com financiamento do Conselho Nacional de Desenvolvimento Científico e Tecnológico (CNPq).

* Doutor em Economia Aplicada pela Universidade Federal de Viçosa. É professor adjunto do Mestrado em Administração da Universidade Federal de Santa Maria. Endereço eletrônico: daniel.coronel@ufv.br.

** Doutor em Economia pela Universidade de Sussex. É professor adjunto e coordenador do Mestrado em Economia da Universidade do Vale do Rio dos Sinos e bolsista de produtividade do CNPq. Endereço eletrônico: aazevedo@unisinos.br.

*** Doutor em Economia Agrícola pela Universidade de Oklahoma. É professor titular do Programa de Pós-Graduação em Economia Aplicada da Universidade Federal de Viçosa e bolsista de produtividade do CNPq. Endereço eletrônico: accampos@ufv.br.
} 
de obra é mais barata. Como consequência, esses países deixaram de produzir bens industriais, especialmente de baixa tecnologia, transferindo sua mão de obra para setores de serviços com maior intensidade tecnológica e níveis de renda e de valor adicionado per capita mais alto, portanto, com salários médios mais altos. Quando esse processo ocorre desta forma, a desindustrialização não é prejudicial. No entanto, em países como o Brasil, que tem uma renda per capita média, sendo que, em 2009, foi de US\$10.465, esse processo de transformação estrutural seria prematuro. Como forma de estancar esse processo, Bresser-Pereira (2010) argumenta que é necessária uma política industrial ativa que gere oportunidades de investimentos lucrativos para os empresários.

Embora vários economistas concordem com a hipótese de que o país vem passando por um processo de desindustrialização, essa questão não é consensual na literatura econômica brasileira. De acordo com Pinheiro e Giambiagi (2006), o setor industrial não está passando por um processo de desindustrialização, mas sim de superação de desafios, tais como altos custos de transação, infraestrutura inadequada, problemas de logística, baixa taxa de investimento público e elevada carga tributária. Neste contexto, como forma de fomentar o setor industrial, o governo de Luís Inácio Lula da Silva lançou, em 2004, a Política Industrial, Tecnológica e de Comércio Exterior (PITCE), a qual, por falta de metas bem definidas e conjuntura desfavorável, não atingiu os objetivos a que se propunha. Em 2008, o Governo Federal lançou a Política de Desenvolvimento Produtivo ${ }^{1}$ (PDP), que tem como objetivo fomentar o setor industrial através de incentivos creditícios, subsídios, isenção e redução de tributos e marcos regulatórios para algumas atividades setoriais.

As metas da PDP são ampliar a capacidade de oferta; preservar a robustez do balanço de pagamentos; elevar a capacidade de inovação; e fortalecer as micro e pequenas empresas. Para alcançá-las, o Governo Federal pretende ampliar o investimento fixo, que, em 2007, perfazia 17,6\% do PIB, para 21\%, em 2010; aumentar os investimentos em pesquisa e desenvolvimento para $0,65 \%$ do PIB; ampliar a participação das exportações brasileiras nas exportações mundiais, de 1,18\%, em 2007, para 1,25\%, no final de 2010; e ampliar em 10\% o número de micro e pequenas empresas exportadoras (BRASIL, 2010). Apesar de esta política ter apresentado, desde o início, alguma falta de clareza e objetividade quanto aos setores que seriam beneficia-

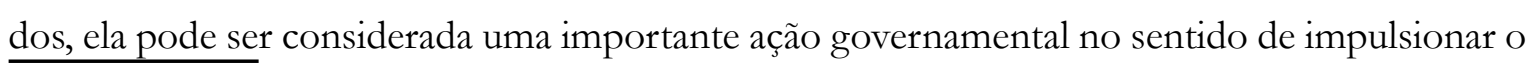
1 A Política de Desenvolvimento Produtivo (PDP) abrange 24 setores da indústria, a saber: Aeronáutico; Agroindústria; Bens de Capital; Bioetanol; Biotecnologia; Carnes; Celulose e Papel; Complexo Automotivo; Complexo de Defesa; Complexo de Serviços; Complexo da Saúde; Construção Civil; Couro, Calçados e Artefatos; Energia Nuclear; Higiene, Perfumaria e Cosméticos; Indústria Naval e de Cabotagem; Madeiras e Móveis; Mineração; Nanotecnologia; Petróleo, Gás e Petroquímica; Plásticos; Siderurgia; Têxtil e Confecções; e Tecnologia da Informação e Comunicação. 
setor industrial, que carecia de ações visando o seu desenvolvimento.

Neste contexto, este estudo procura examinar os impactos econômicos de mudanças nas alíquotas de tributação, contidas na Política de Desenvolvimento Produtivo, nos níveis de bem-estar e no consumo aparente. O presente trabalho está estruturado em três seções, além desta introdução. $\mathrm{Na}$ segunda seção, são apresentados os procedimentos metodológicos; na terceira, os resultados obtidos são analisados e discutidos e, finalmente, na última seção, são apresentadas algumas considerações sobre o trabalho.

\section{METODOLOGIA}

\subsection{MODELO ANALÍTICO}

O modelo GTAPinGAMS², a ser utilizado neste estudo, foi desenvolvido a partir do modelo Global Trade Analysis Project (GTAP). O GTAPinGAMS, de acordo com Broocke (1998), utiliza a base de dados do GTAP, sendo elaborado como um problema de complementaridade não linear, em linguagem de programação General Algebraic Modeling System (GAMS).

O GTAPinGAMS pode ser caracterizado como estático, multirregional e representando a produção e distribuição de bens na economia mundial. No GTAPinGAMS, o mundo é dividido em regiões, sendo que cada região tem uma estrutura de demanda final composta de gastos públicos e privados com os bens. O modelo é baseado no comportamento otimizador dos agentes, uma vez que os consumidores maximizam o bem-estar sujeitos à sua restrição orçamentária, dados os níveis fixos de investimento e gastos públicos. O processo produtivo, por sua vez, combina insumos intermediários com fatores primários, os quais são trabalho qualificado e não qualificado, terra, recursos naturais e capital físico, com vistas a minimizar custos de produção, sujeitos a uma determinada tecnologia. A base de dados do modelo inclui os fluxos de comércio bilaterais entre as regiões, associados aos custos de transporte, impostos às exportações e tarifas às importações, associados aos fluxos de comércio (RUTHERFORD, 2005).

O modelo usa uma estrutura aninhada em três níveis na especificação da função de produção. No topo, a função de produção assume substituibilidade zero entre os fatores primários de produção e os insumos intermediários (tecnologia de Leontief), sendo que o mix ótimo de fatores primários é independente dos preços dos insumos intermediários, enquanto o mix ótimo de insumos intermediários não varia conforme o preço dos fatores primários. O segundo ninho envolve uma elasticidade de substituição constante, tanto entre os insumos como entre

2 Para maiores informações sobre as equações comportamentais do modelo GTAPinGAMS, ver Coronel (2010). 
os fatores primários de produção. Parte-se do pressuposto de que os insumos importados são diferenciados por origem, assim como os insumos domésticos são discriminados em relação aos importados. Isto é, as firmas inicialmente determinam o mix ótimo de insumos domésticos e importados e somente depois decidem a respeito da origem das importações (hipótese de Armington). O nível mais baixo do ninho também assume uma elasticidade de substituição constante entre os insumos importados de diferentes origens.

\subsection{FECHAMENTO MACROECONÔMICO UTILIZADO E RETORNOS DE ESCALA}

Neste trabalho, o fechamento macroeconômico utilizado foi o neoclássico. De acordo com Feijó e Azevedo (2006), o modelo neoclássico, ao contrário dos fechamentos não neoclássicos que consideram o investimento fixo, permite se ajustar às variações na poupança. Ainda segundo os autores, os fatores que têm mobilidade entre os setores são capital, mão de obra qualificada e não qualificada, sendo que o grau de mobilidade dos fatores de produção é governado por uma elasticidade de transformação constante, e terra e recursos naturais são fatores de produção parcialmente móveis.

\subsection{BANCO DE DADOS, AGREGAÇÃO E SOFTWARE UTILIZADO}

O banco de dados utilizados neste trabalho é o do Global Trade Analysis Project (GTAP), versão 7, com base de dados para 2004, sendo que esta versão compreende 113 regiões, 57 commodities e 5 fatores de produção. Em função das limitações da base de dados do GTAP, apenas 13 setores serão analisados (Tabela 1) daqueles contidos na Política de Desenvolvimento Produtivo (PDP), sendo os demais agregados na categoria dos demais setores.

TABELA 1 - AGREGAÇÃO ENTRE REGIÕES E COMMODITIES REALIZADAS NO GTAP

\begin{tabular}{ll}
\hline \multicolumn{1}{c}{ Regiões } & \multicolumn{1}{c}{ Setores } \\
\hline 1. Brasil (BRA) & 1. Têxtil e Confecções (TXT) \\
2. MERCOSUL (MER) & 2. Petróleo, Gás e Petroquímica (PET) \\
3. Estados Unidos (EUA) & 3. Mineração (MIN) \\
4. União Europeia-25 (EUR) & 4. Couro, Calçados e Artefatos (COU) \\
5. BRIC (BRIC) & 5. Madeira e Móveis (MAD) \\
6. Resto do Mundo (RMD) & 6. Celulose e Papel (CEL) \\
& 7. Plásticos (PLA) \\
& 8. Siderurgia (SID) \\
9. Complexo Automotivo (AUT) & 10. Bens de Capital (BC) \\
& 11. Construção Civil (CIV) \\
12. Indústria Naval e de Cabotagem (NAV) & 13. Aeronáutico (AER) \\
14. Demais Setores (DEM)
\end{tabular}

FONTE: Elaborado a partir do GTAP-7.

NOTA: Os símbolos entre parênteses indicam os códigos utilizados para a estimação. 
No que tange à agregação setorial, além do Brasil, a mesma contempla os principais parceiros comerciais do país, incluindo: Mercado Comum do Sul (MERCOSUL), sem o Brasil, o qual terá como base a sua formação inicial com Argentina, Paraguai e Uruguai; Estados Unidos da América (EUA); União Europeia ${ }^{3}$ (25); BRIC, sem o Brasil, o qual é composto por China, Índia e Rússia; enquanto os demais países foram agregados na categoria resto do mundo.

\subsection{CENÁRIO ANALÍTICO}

Para alcançar os objetivos do estudo e fundamentado nas proposições contidas na Política de Desenvolvimento Produtivo (PDP), explicitadas em Brasil (2010) e ABDI (2008, 2009a, 2009b, 2009c), propõe-se analisar o impacto dessa política nos 13 setores produtivos descritos anteriormente, aplicando-se as reduções do IPI e do ICMS propostas pela PDP.

A análise de resultados dos impactos setoriais da PDP foi realizada para os agrupamentos dos setores em diferentes níveis de intensidade tecnológica, conforme a classificação da Organização para a Cooperação e Desenvolvimento Econômico - OCDE (2010), visto que a análise individual de cada setor implicaria, muitas vezes, em discussões prolixas. Além disso, a análise em agrupamentos setoriais permite visualizar melhor para quais níveis tecnológicos a política foi mais adequada. Esta classificação também é defendida por autores de cunho ortodoxo, que defendem que as políticas industriais devem favorecer setores intensivos em tecnologia. O agrupamento setorial pode ser mais bem visualizado na Tabela 2.

TABELA 2 - CLASSIFICAÇ̃̃O SETORIAL COM BASE NOS NÍVEIS DE INTENSIDADE TECNOLÓGICA

\begin{tabular}{|c|c|c|c|}
\hline $\begin{array}{c}\text { Setores de } \\
\text { baixa intensidade } \\
\text { tecnológica }\end{array}$ & $\begin{array}{c}\text { Setores de } \\
\text { média-baixa intensidade } \\
\text { tecnológica }\end{array}$ & $\begin{array}{c}\text { Setores de } \\
\text { média-alta intensidade } \\
\text { tecnológica }\end{array}$ & $\begin{array}{c}\text { Setores de } \\
\text { alta intensidade } \\
\text { tecnológica }\end{array}$ \\
\hline $\begin{array}{l}\text { Têxtil e Confecções } \\
\text { Couros, Calçados e Artefatos } \\
\text { Madeira e Móveis } \\
\text { Celulose e Papel }\end{array}$ & $\begin{array}{l}\text { Petróleo, Gás e Petroquímica } \\
\text { Mineração } \\
\text { Siderurgia } \\
\text { Plásticos } \\
\text { Naval e Cabotagem }\end{array}$ & $\begin{array}{l}\text { Automotivo } \\
\text { Bens de Capital }\end{array}$ & $\begin{array}{l}\text { Aeronáutica } \\
\text { Construção Civil }\end{array}$ \\
\hline
\end{tabular}

\section{ANÁLISE E DISCUSSÃO DOS RESULTADOS}

\subsection{ANÁLISE DOS IMPACTOS DA POLÍTICA DE DESENVOLVIMENTO PRODUTI- VO (PDP)}

De acordo com a Tabela 3, dos 13 setores analisados, 10 apresentaram aumentos na

3 Os 25 países da União Europeia são: Alemanha; Áustria; Bélgica; Chipre; Dinamarca; Eslováquia; Eslovênia; Espanha; Estônia; Finlândia; França; Grécia; Hungria; Irlanda; Itália; Letônia; Lituânia; Luxemburgo; Malta; Países Baixos; Polônia; Portugal; Reino Unido; República Tcheca e Suécia. 
relação produção menos exportações sobre o consumo aparente e decréscimos na relação importações sobre o consumo aparente, ou seja, a PDP contribuiu para aumentar ainda mais o viés doméstico do consumo brasileiro na maior parte dos setores analisados, o que é o objetivo de todas as políticas industriais.

Um aspecto importante a ser considerado é que, tanto no equilíbrio inicial como no final, para todos os setores analisados, a taxa de suprimento do consumo doméstico na economia brasileira é fortemente dependente da produção doméstica, pois em nenhum dos equilíbrios analisados a participação das importações supera a da produção doméstica. Isso pode ser corroborado pelos resultados da Tabela 3, que mostram que, dos 13 setores analisados, em 10 o consumo depende em mais de $75 \%$ da produção doméstica.

Os setores de baixa tecnologia, representados pelos setores Têxtil e de Confecções; Couro, Calçados e Artefatos; Madeira e Móveis; e Celulose e Papel, apresentaram aumentos na relação produção menos exportação sobre consumo aparente e decréscimo na relação importações sobre o consumo aparente, o que indica que as medidas setoriais da PDP para essas atividades industriais conseguiram aumentar a participação da produção doméstica no autossuprimento em detrimento das importações.

TABELA 3 - EFEITO DA PDP SOBRE A PARTICIPAÇÃO BRASILEIRA NO CONSUMO APARENTE RESULTANTE DA IMPLEMENTAÇÃO DA PDP

\begin{tabular}{|c|c|c|c|c|c|}
\hline \multirow{2}{*}{$\begin{array}{l}\text { Intensidade } \\
\text { tecnológica }\end{array}$} & \multirow{2}{*}{ Setores } & \multicolumn{2}{|c|}{ P-X/CA } & \multicolumn{2}{|c|}{$\mathrm{M} / \mathrm{CA}$} \\
\hline & & Inicial & Final & Inicial & Final \\
\hline \multirow{4}{*}{ Baixa } & TXT & 92,35 & 92,62 & 7,65 & 7,38 \\
\hline & $\mathrm{COU}$ & 89,50 & 90,34 & 10,50 & 9,66 \\
\hline & MAD & 96,27 & 96,49 & 3,73 & 3,51 \\
\hline & CEL & 95,40 & 95,55 & 4,60 & 4,45 \\
\hline \multirow{5}{*}{ Média-Baixa } & PET & 85,34 & 84,31 & 14,66 & 15,69 \\
\hline & MIN & 92,13 & 92,14 & 7,87 & 7,86 \\
\hline & SID & 93,34 & 93,48 & 6,66 & 6,52 \\
\hline & PLA & 76,28 & 76,30 & 23,72 & 23,70 \\
\hline & NAV & 62,09 & 62,08 & 37,91 & 37,92 \\
\hline \multirow{2}{*}{ Média-Alta } & AUT & 86,37 & 87,68 & 13,63 & 12,32 \\
\hline & $\mathrm{BCP}$ & 69,19 & 71,15 & 30,81 & 28,85 \\
\hline \multirow{2}{*}{ Alta } & AER & 69,12 & 69,16 & 30,88 & 30,84 \\
\hline & CIV & 99,96 & 99,96 & 0,04 & 0,04 \\
\hline
\end{tabular}

FONTE: Resultados da pesquisa.

Os setores de baixa-média tecnologia, representados pelos setores de Petróleo, Gás e Petroquímica; Mineração; Plástico; Siderurgia e Indústria Naval e de Cabotagem, à exceção do setor de Petróleo, Gás e Petroquímica e Indústria Naval e de Cabotagem, apresentaram, em sua maioria, aumento da produção menos exportações sobre o consumo aparente e redução das importações sobre o consumo aparente. Consequentemente, as medidas da PDP aumentaram a 
dependência externa somente em recursos energéticos, o que constitui um resultado negativo.

Os setores de média-alta tecnologia, representados pelo setor Automotivo e Bens de Capital, apresentaram aumentos na relação produção menos exportação e decréscimo na relação importações sobre o consumo aparente, indicando que a política conseguiu estimular a participação da produção doméstica no consumo aparente em detrimento das importações. Admitindo-se que houve uma expansão acelerada da frota nacional de veículos, conforme o IPEA (2010), as medidas da PDP para o setor Automotivo devem ser vistas como um instrumento que foi aplicado para contornar parte dos problemas relacionados com a crise econômica mundial. No entanto, faz-se necessário avaliar os custos e benefícios de tais medidas em um horizonte de prazo maior.

A análise para o setor Aeronáutico indica que não houve alterações substanciais nas relações das participações da produção doméstica e das importações sobre o consumo aparente. A retração da produção foi acompanhada de queda no consumo, e as quedas nas exportações e importações foram compensadas entre si. A Construção Civil não apresentou variações nas participações da produção e das importações sobre o consumo aparente.

Em relação aos fatores primários de produção, foram observados aumentos das remunerações dos fatores terra e trabalho (não qualificado e qualificado), conforme a Tabela 4. Assim, as medidas da PDP contribuíram para o crescimento da demanda derivada desses fatores. O aumento da remuneração da mão de obra qualificada e não qualificada sinaliza que existe espaço para a expansão do emprego doméstico, principalmente nos setores caracterizados como sendo intensivos em baixa e em média-baixa tecnologias.

TABELA 4 - VARIAÇÃO PERCENTUAL NA REMUNERAÇÃO DOS FATORES E NA LUCRATIVIDADE DO CAPITAL PARA O BRASIL DEVIDO ÀS MEDIDAS PROPOSTAS PELA PDP

\begin{tabular}{lrr}
\hline \multicolumn{1}{c}{ Fatores } & Brasil \\
\hline Terra & 4,127 \\
Trabalho não qualificado & 5,137 \\
Trabalho qualificado & 4,447 \\
Capital & 5,483 \\
Lucratividade do capital & 58,566 \\
\hline
\end{tabular}

FONTE: Resultados da pesquisa.

A lucratividade do capital tem como finalidade medir o retorno ao capital em termos de custo de formação desse capital, sendo calculada pela relação entre a taxa de retorno ao capital e o custo unitário do investimento. Esta relação pode ser interpretada da seguinte forma: a redução da lucratividade do capital indica uma desvalorização do fator capital relativamente ao custo de investimento, enquanto um aumento na lucratividade do capital indica que o gasto com a formação do capital se torna mais atrativo, uma vez que o preço do capital gerado pelo 
investimento é relativamente maior. Como o resultado foi positivo (Tabela 4), pode-se afirmar que os investimentos produtivos na economia tornam-se mais lucrativos após a implementação das medidas de incentivo tributário da PDP, o que era uma das metas da política.

As mudanças nos níveis de bem-estar (Gráfico 1) são medidas pelo conceito de variação equivalente e expressam, em termos percentual e monetário, as variações nos níveis de utilidade auferidos pelos agentes econômicos. Os resultados indicam que os ganhos de bemestar são positivos para o Brasil, o que significa que os incentivos tributários contidos na PDP promovem aumentos no nível de bem-estar para os consumidores brasileiros, provavelmente pelos resultados já discutidos anteriormente. Em valores absolutos, os ganhos de bem-estar mostram-se expressivos, em torno de US\$ 3 bilhões para a economia brasileira. Esse valor indica que, mesmo a variação de bem-estar sendo relativamente pequena em termos percentuais, é expressiva em termos absolutos. Tais resultados podem ser corroborados pelo trabalho de Silva e Cavalcanti (2009) os quais, analisando algumas medidas relacionadas à PDP, constaram que, se as reduções tributárias fossem maiores, essa política de expansão do consumo poderia gerar efeitos significativos sobre a taxa de crescimento da economia no curto prazo.

GRÁFICO 1 - GANHOS DE BEM-ESTAR, MEDIDOS PELA VARIAÇÃO EQUIVALENTE (EM US\$ BILHÕES), RESULTANTES DA IMPLEMENTAÇÃO DA PDP

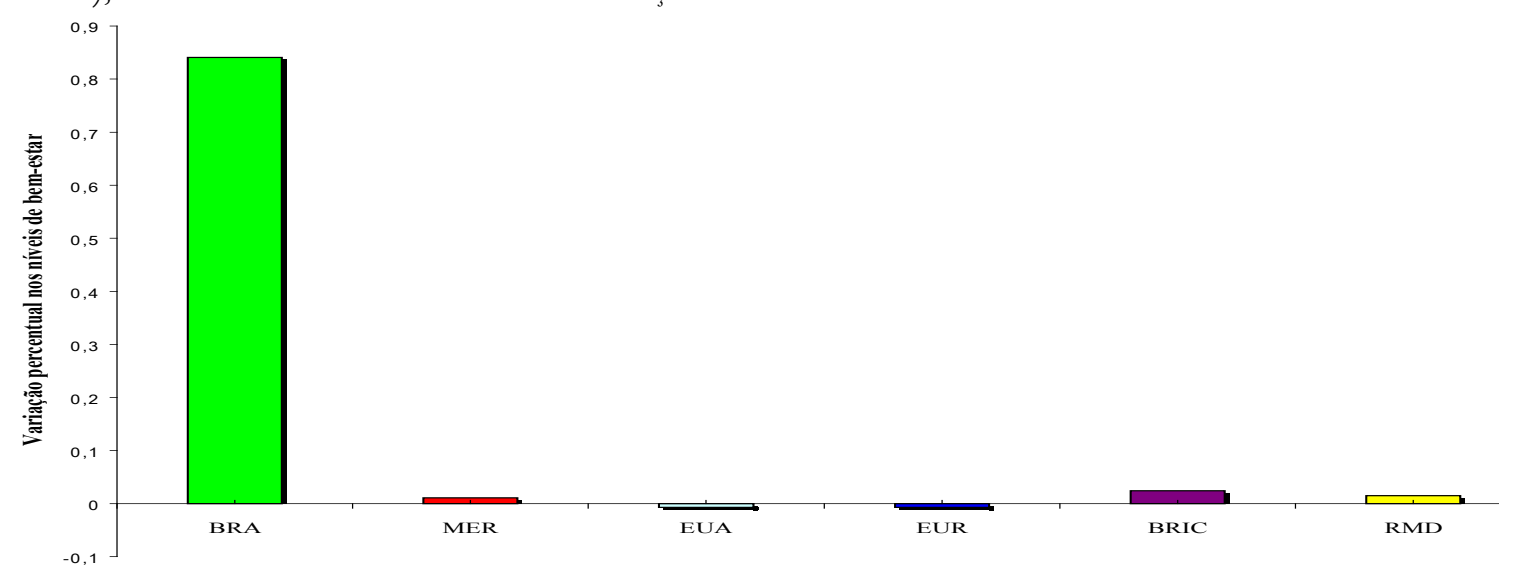

FONTE: Resultados da pesquisa.

Em relação aos principais parceiros econômicos do país, as oscilações verificadas são de pequenas magnitudes, conforme esperado, visto que o Brasil ainda não tem uma pujança no comércio mundial a ponto de alterar substancialmente a estrutura econômica de seus parceiros. No entanto, convém destacar que, em valores monetários, os Estados Unidos e a União Europeia experimentaram perdas de aproximadamente US\$ 1 bilhão com as medidas propostas pela PDP. 


\section{CONCLUSÕES}

Os resultados da simulação feita com base na implementação das medidas contidas na PDP mostraram que tal política contribuiu para o aumento da produção doméstica no consumo aparente de dez dos trezes setores analisados, contudo tal política não foi eficaz para os setores de alta-tecnologia. No que tange aos níveis de bem-estar, pode-se observar que a mesma foi significativa, visto que possibilitou aumento na ordem de US\$ 3 bilhões.

A partir destes resultados, algumas questões merecem ser analisadas, tais como o impacto da PDP nas regiões e nos estados brasileiros e o efeito destas políticas nas finanças públicas nacionais e estaduais. Essas questões são importantes desafios que se colocam para os formuladores de políticas públicas e para pesquisadores que estudam os impactos econômicos das políticas industriais.

\section{REFERÊNCIAS}

AGÊNCIA BRASILEIRA DE DESENVOLVIMENTO INDUSTRIAL. GPS da indústria: medidas legais. Brasília, 2008.

AGÊNCIA BRASILEIRA DE DESENVOLVIMENTO INDUSTRIAL. GPS da indústria: medidas legais. Brasília, 2009a.

AGÊNCIA BRASILEIRA DE DESENVOLVIMENTO INDUSTRIAL. GPS da indústria: medidas legais. Brasília, 2009b.

AGÊNCIA BRASILEIRA DE DESENVOLVIMENTO INDUSTRIAL. GPS da indústria: medidas legais. Brasília, 2008c.

BRASIL. Ministério do Desenvolvimento, Indústria e Comércio Exterior. Política de Desenvolvimento Produtivo (PDP). Disponível em: < http://www.mdic.gov.br/pdp/index.php/sitio/inicial>. Acesso em: 4/8/2010.

BRESSER-PEREIRA, L. C. Desindustrialização e câmbio. Disponível em: <http://www. bresserpereira.org.br/Papers/Interviews/2010/10.09.Entrevista_Bresser-NI.pdf.> Acesso em: $14 / 10 / 2010$.

BROOKE, A. GAMS: a user'guide. GAMS Development Corporation, 1998.

CORONEL, D. A. Impactos da política de desenvolvimento produtivo na economia brasileira. Tese (Doutorado em Economia Aplicada) - Universidade Federal de Viçosa, Viçosa, 2010.

FEIJÓ, F. T.; AZEVEDO, A. F. Z. D. Comércio e meio ambiente: políticas ambientais e competitividade no âmbito da ALCA. Revista de Economia Aplicada, São Paulo, v. 10, n. 4, p. 561-587, 2006.

INSTITUTO DE PESQUISA ECONÔMICA APLICADA. Impactos da redução do imposto sobre produtos industrializados (IPI) de automóveis. Brasília, 2010. Nota técnica.

ORGANIZAÇÃO PARA A COOPERAÇÃO E DESENVOLVIMENTO ECONÔMICO. Industry and entrepreneurship. Disponível em: <http://www.oecd.org/topic/0,3373, en_ 2649_37461_1_1_1_1_37461,00.html>. Acesso em: 28/10/2010. 
PINHEIRO, A. C.; GIAMBIAGI, F. Rompendo o marasmo: a retomada do desenvolvimento no Brasil. Rio de Janeiro: Elsevier, 2006.

RUTHERFORD, T. H. GTAP6inGAMS: the dataset and static model. Colorado: University of Colorado, 2005.

SILVA, N. L. C. D.; CAVALCANTI, M. A. F. H. Impactos de políticas de desoneração do setor produtivo: uma avaliação a partir de um modelo de geração sobrepostas. Brasília: IPEA, 2009. Discussão. 